\title{
The Use of Temporal Check-All-That-Apply and Category Scaling by Experienced Panellists to Evaluate Sweet and Dry Ciders
}

\author{
Rachael Moss, Sophie Barker and Matthew B. McSweeney *D
}

check for

updates

Citation: Moss, R.; Barker, S.;

McSweeney, M.B. The Use of

Temporal Check-All-That-Apply and

Category Scaling by Experienced

Panellists to Evaluate Sweet and Dry

Ciders. Beverages 2021, 7, 24. https://

doi.org/10.3390/beverages7020024

Academic Editors: Anna

Picinelli-Lobo and Christian Ariel

Lopes

Received: 19 April 2021

Accepted: 14 May 2021

Published: 17 May 2021

Publisher's Note: MDPI stays neutral with regard to jurisdictional claims in published maps and institutional affiliations.

Copyright: (c) 2021 by the authors. Licensee MDPI, Basel, Switzerland. This article is an open access article distributed under the terms and conditions of the Creative Commons Attribution (CC BY) license (https:// creativecommons.org/licenses/by/ $4.0 /)$.
School of Nutrition and Dietetics, Acadia University, Wolfville, NS B4P 2R6, Canada; 145961m@acadiau.ca (R.M.); 142275b@acadiau.ca (S.B.)

* Correspondence: matthew.mcsweeney@acadiau.ca

\begin{abstract}
Cider is a growing market in North America, but more studies need to be completed to fully understand ciders' sensory properties. The primary objective of this study was to identify the differences in the sensory properties of ciders described as "sweet" or "dry" using both static (category scales) and dynamic (temporal check-all-that-apply, TCATA) sensory methodologies. The secondary objective was to evaluate experienced panellists with a familiar methodology (category scales) and an unfamiliar methodology (TCATA). The sweet ciders were characterized by sweet, floral, cooked apple, and fresh apple attributes, and they had a sour aftertaste. The dry ciders were found to be bitter, sour, earthy, and mouldy, and they had a sour and bitter aftertaste. The experienced panellists produced reproducible results using both methodologies; however, they did not find small differences between the cider samples. Future research should investigate a wider range of cider and investigate ciders' aftertaste. More studies need to be completed on experienced panellists and on when researchers and the food industry should use them.
\end{abstract}

Keywords: cider; temporal check-all-that-apply; experienced panellists; alcoholic beverages

\section{Introduction}

Cider is a sparkling alcoholic beverage produced by fermentation of apples and has a range of alcoholic contents and flavour characteristics [1]. Production and consumption of cider continue to grow around the world [2]. However, knowledge about cider's sensory properties is limited [3]. Cider has many different sensory attributes of interest, including colour, turbidity, aroma, acidity, astringency, sweetness, and carbonation, based on the different production techniques and apple varieties [4]. Past research has shown that apple variety [5,6], fruit ripeness [7], fermentation conditions [2,8], and yeast strains [9] all affect the sensory properties of the resulting cider. The primary sensory properties of apple ciders are spicy, aromatic, and apple-like notes [1].

Recent studies on cider had focused on the chemical composition, phenolic compounds, amino acids, sugars, and organic acids in ciders [10-15]. Little information is available regarding the sensory properties of ciders that are on the market, especially those that are available on the Canadian market (specifically the province of Nova Scotia in this study). Ciders are usually characterized as dry or "brut", half dry or "demi-sec", or sweet or "doux" [16]. However, this categorization is usually simplified to marketing the cider as sweet and dry on the North American market [17]. This is a simplified classification that helps consumers understand the sensory properties of cider. For the cider market to continue to grow, more studies involving cider and sensory analysis are needed.

Descriptive analysis uses trained panellists for developing a comprehensive and objective description of the sensory properties of food items [18]. Trained panellists are selected based on their sensory acuity and their ability to discriminate between the different products [19]. After the panellists are recruited, they receive extensive training to learn about 
the background of the food or beverages being tested and the evaluation method [20]. The trained panellists can provide precise information, including the detection of small differences in the products being studied [18]. However, trained panels or descriptive analysis require lots of time, resources, and money. Due to these constraints, some researchers have chosen to use experienced panellists. Experienced panellists are individuals who are either highly experienced with the food product being tested and the method being used or who have received extensive training before the testing [21]. Previous research has investigated panellists who have extensive experience with the sensory method being used and found that the experienced panellists had similar descriptions to trained panellists [22]. This result was also found when experienced panellists and trained panellists evaluated wine [23]. This study will build on this research by asking experienced panellists, who have extensive experience with sensory trials, to evaluate ciders using a method they are not familiar with: temporal check-all-that-apply.

Temporal check-all-that-apply (TCATA) extends the use of check-all-that-apply (CATA) questions by allowing for continuous selection and deselection of the attributes based on their applicability in describing the sample [24]. The participant's task is to indicate and update the attributes that apply to the sample from moment to moment [24]. TCATA allows the research to track the sample as it changes over time [24]. This method builds on past research because sensory perception is temporal, not a static experience [25]. TCATA is an effective technique for capturing dynamic sensory evaluation information similar to temporal dominance of sensations and time intensity [26]. TCATA builds on these methods by allowing for concurrent attribute selection and has been used to effectively evaluate complex products such as alcoholic beverages, including wine $[25,27,28]$ and beer [29].

In this context, the experienced panellists used static (category scales) and dynamic sensory evaluation methods (TCATA) to evaluate the differences between dry and sweet ciders. Secondly, the results of the experienced panellists were evaluated for consistency.

\section{Materials and Methods}

\subsection{Experienced Panellists}

Approval for the study was received from the Acadia University Research Ethics Board (REB 21-16). Experienced panellists were recruited from a list of participants who have previously participated in sensory testing and regularly consumed cider (self-identified). All participants were 19 years of age or older, as this is the legal drinking age in the province of Nova Scotia, Canada, and did not work in the cider industry. The participants were composed of 16 panellists who had participated in sensory trials before (6 males and 10 females; mean age $32.4 \pm 5.3$ ). The experienced panellists were screened to ensure they had previously been involved in a trained panel evaluating an alcoholic beverage (mainly beer or wine). Additionally, all experienced panellists had participated in sensory trials using category scales, CATA, projective mapping, and ultra-flash profiling methodologies (the mean number of sensory trials the panellists had previously participated in was 4.3).

\subsection{Testing Environment}

All testing was completed at the Centre for the Sensory Research of Food at Acadia University, using individual sensory booths. The trials took place in the booths under white fluorescent light, at a temperature of $25^{\circ} \mathrm{C}$, and in a ventilated area.

\subsection{Samples and Sample Presentation}

Five different ciders available for purchase in Nova Scotia, Canada, were evaluated. Three of the ciders were described as "sweet", and the two other ciders were described as "dry". Descriptive details of the cider samples are listed in Table 1. The $\mathrm{pH}$ of the cider was tested using a Thermo Scientific $\mathrm{pH}$ meter (Waltham, MA, USA). The percentages of solids (Brix) were measured using a digital refractometer (Table 1). One sample was presented twice (D2) to the panellists to evaluate the consistency of the results, so each panellist received six cider samples. For all sensory trials, samples were prepared and 
presented following the same procedure. Each cider's sample size was $50 \mathrm{~mL}$, and the samples were presented in a small, transparent standard ISO wine glass. All cider bottles and cans were stored in the fridge $\left(4^{\circ} \mathrm{C}\right)$ until $10 \mathrm{~min}$ before testing began when they were removed from the fridge. The cider samples were poured approximately $30 \mathrm{~s}$ before being served to the panellists. Each sample was sealed with Parafilm to reduce the potential loss of carbonation. The samples were all labelled with random three-digit codes identified on the glass. Each panellist was also provided with a glass of filtered water to cleanse their palates.

Table 1. Physico-chemical and market characteristics of the ciders evaluated.

\begin{tabular}{ccccccc}
\hline Cider & Type & Brix & $\mathbf{p H}$ & Alcohol Percentage & Packaging & Price (CAD) \\
\hline S1 & Sweet & 5.6 & 3.4 & $6.0 \%$ & $473 \mathrm{~mL}$ Can & 4.99 \\
\hline S2 & Sweet & 6.4 & 3.6 & $5.3 \%$ & $500 \mathrm{~mL}$ Bottle & 4.75 \\
\hline S3 & Sweet & 6.0 & 3.6 & $5.8 \%$ & $500 \mathrm{~mL}$ Bottle & 4.75 \\
\hline D1 & Dry & 4.5 & 3.7 & $6.5 \%$ & $500 \mathrm{~mL}$ Bottle & 4.69 \\
\hline D2 & Dry & 4.3 & 3.9 & $6.0 \%$ & $500 \mathrm{~mL}$ Bottle & 4.29 \\
\hline
\end{tabular}

\subsection{Procedure}

Before starting the testing, a consent form containing information about the study, the purpose, and the ingredients was provided. The experienced panellists were informed there would be two different sessions of approximately $1 \mathrm{~h}$. The panellists were led in a short training session (less than $20 \mathrm{~min}$ ) discussing the different sensory properties of the cider samples, and they were given a list of definitions for the sensory attributes (Table S1: Attributes evaluated by the experienced panellists). In the first session, the experienced panellists were presented with six cider (five different ciders and one replicate sample, D2) samples (one at a time) following a randomized complete block design. The experienced panellists were asked to drink a mouthful of cider and to evaluate the samples for the intensity of appearance (clarity, carbonation), aroma (floral, fresh apple, cooked apple, citrus, banana, yeasty, chemical, earthy, perfume, mouldy), taste (sweet, sour, bitter, salty), and mouthfeel (astringency, acidic, tannic) attributes on a category scale from $1=$ Low to $9=$ High, with a $0=$ None option [30]. The attributes were included based on evaluation of the ciders by research assistants who have extensive experience working on sensory trials and on a literature review [1,3,10,16,30-34]. In between each sample, the experienced panellists took a thirty-second break and had a drink of filtered water to cleanse their palates. After they completed the evaluation, the experienced panellists were asked to complete a CATA question including all of the sensory properties (clarity, carbonation, floral, fresh apple, cooked apple, citrus, banana, yeasty, chemical, earthy, perfume, mouldy, sweet, sour, bitter, salty, astringency, acidic, tannic). The CATA question presented a list of terms to the participants [35]. The experienced panellists were instructed to select the attributes they felt were most important when evaluating cider. This testing was completed using a paper questionnaire.

In the second session, the experienced panellists completed the TCATA task. The selection of the eight attributes (sweet, sour, bitter, yeasty, earthy, fresh apple, cooked apple, and chemical) was based on the CATA question asked above. The most frequently selected terms were included in the TCATA task. The attributes were presented according to a Williams experimental design with an attribute list allocated to the experienced panellists such that the position of the attribute was consistent across evaluations [36]. The procedure for the TCATA task was adapted from Mitchell et al. [29]. The experienced panellists once again received training about the sensory attributes (sweet, sour, bitter, yeasty, earthy, fresh apple, cooked apple, and chemical) and were also trained on the TCATA methodology. They also received instructions on the questionnaire itself. The training involved orally discussing the eight attributes in the TCATA task and ensuring that all experienced panellists understood the definitions of the attributes. One of the 
researchers demonstrated the TCATA task for the experienced panellists. The researchers answered all questions from the experienced panellists.

The evaluation of the six cider samples (five different ciders and one replicate sample; D2) was completed using Compusense Cloud Software (Academic Consortium; Guelph, ON, Canada). The experienced panellists were asked to take a normal to full-sized amount of the cider [37] and concurrently press the Start button. They were asked to hold the cider in their mouth and to avoid swishing or gurgling. The experienced panellists were asked to select all of the attributes they were experiencing at the time. They were instructed to hold the sample in their mouth for $10 \mathrm{~s}$, and then they were asked to swallow the sample but continue to click all the attributes they were experiencing. The panellists were informed that each selected term fades after $5 \mathrm{~s}$, and that they had to re-select the term if it still applied at that moment. If they were not experiencing any sensations, they were asked not to click on any of the attributes. The evaluation of each sample lasted $90 \mathrm{~s}$. The panellists took a $30 \mathrm{~s}$ break between each sample and had a drink of filtered water to cleanse their palates.

\subsection{Statistical Analysis}

A two-way Analysis of Variance (ANOVA) followed by a Tukey's Honest Significant Difference (HSD) test was completed to determine any significant differences in the sensory properties between the different samples. The frequency of attributes identified by experienced panellists in the CATA task was summed. For the TCATA, the proportions of citations were calculated as the percentage of panellists who clicked an attribute at a given moment during the evaluation period $[24,25]$. Graphs were produced by the Compusense Cloud Software (Guelph, Ontario, Canada). TCATA difference plots for the replicated cider (D2) were obtained by subtracting their citation proportion per Ares et al. [38]. The analysis of the average proportion of citations followed a similar method to McMahon et al. [28]. As described by McMahon et al. [28], the average proportion of the citations for each attribute in each TCATA evaluation is the proportion of the $90 \mathrm{~s}$ evaluation time that the attribute was selected. For instance, if a panellist selected bitter for a duration of $30 \mathrm{~s}$, then the proportion of citation for bitter would be $30.0 / 90.0=0.33$. The proportion of citations ranged from 0 to 1 . Sample differences were evaluated using differences in the least square means $(p<0.05)$. All analysis was completed using XLSTAT software (Version 2020.1, New York, NY, USA) in Microsoft Excel ${ }^{\mathrm{TM}}$.

\section{Results and Discussion}

The results of the category scales are presented in Table 2 for the cider samples. The experienced panellists produced consistent results as the dry cider, D2 presented twice, had similar scores for all sensory properties $(p<0.05)$. There were no significant differences in the carbonation of the different ciders $(p<0.05)$, but there was a significant difference in the clarity of the ciders. S1 and D2 were significantly less clear than the other ciders $(p<0.05)$. This difference in the clarity may affect the experienced panellists ' evaluation of the ciders as the appearance of unfiltered ciders led to different consumer expectations [39] and a study on apple juices found that cloudy apple juices were not as well-liked as clear apple juices [40].

The experienced panellists did separate the "sweet" (S1, S2, S3) and "dry" (D1, D2, D2 replicate) ciders based on a number of the sensory properties. The experienced panellists indicated that the sweet ciders had a significantly higher aroma intensity of floral and cooked apple than the dry ciders $(p<0.05)$. Past research has found that ciders associated with fruity and flowery flavours are also associated with the cooked apple flavour [16]. This result was found in this study as well, as the ciders that scored the highest in floral aroma were also described as having a cooked apple aroma. This result is also supported by the findings of a study on ciders from the United Kingdom and the Scandinavian region [1], as the researchers found that floral and fruity aromas were clustered with a sweet taste. The study on ciders from the United Kingdom and the Scandinavian region [1] also found that cooked apple aroma was associated with citrus, sour, and bitter; however, this was not 
found in this study, and this may be due to differences in the geographical locations of the apple production. The dry ciders were found to be significantly higher in earthy aroma than the sweet ciders; this result was reinforced by the findings of Jamir et al. [41], as they found that American consumers described dry cider as being earthy or having a damp earth aroma.

Table 2. Intensities (mean \pm standard deviation) of the sensory attributes for the different ciders.

\begin{tabular}{|c|c|c|c|c|c|c|}
\hline Attribute & S1 & S2 & S3 & D1 & D2 & D2 \\
\hline \multicolumn{7}{|l|}{ Appearance } \\
\hline Clarity ${ }^{1}$ & $5.6^{\mathrm{a}} \pm 1.1$ & $7.2^{b} \pm 1.3$ & $6.2^{\mathrm{ab}} \pm 1.5$ & $6.6^{\mathrm{ab}} \pm 1.3$ & $5.4^{\mathrm{a}} \pm 1.5$ & $5.6^{a} \pm 1.6$ \\
\hline $\begin{array}{c}\text { Carbonation } \\
\text { Aroma }\end{array}$ & \multicolumn{5}{|c|}{ Aroma } & $2.9^{\mathrm{a}} \pm 1.0$ \\
\hline Floral & $5.0^{\mathrm{a}} \pm 1.2$ & $5.1^{\mathrm{a}} \pm 1.3$ & $5.5^{\mathrm{a}} \pm 1.5$ & $4.0^{\mathrm{b}} \pm 1.1$ & $3.8^{\mathrm{b}} \pm 1.2$ & $3.8^{\mathrm{b}} \pm 1.3$ \\
\hline Fresh Apple & $4.9^{\mathrm{ab}} \pm 0.9$ & $4.3^{\mathrm{ab}} \pm 1.2$ & $4.7^{\mathrm{ab}} \pm 1.2$ & $5.2^{\mathrm{a}} \pm 1.4$ & $3.0^{c} \pm 1.2$ & $3.2^{\mathrm{c}} \pm 1.2$ \\
\hline Cooked Apple & $3.4^{\mathrm{a}} \pm 1.0$ & $3.3^{\mathrm{a}} \pm 1.0$ & $3.1^{\mathrm{a}} \pm 1.0$ & $2.1^{b} \pm 0.9$ & $2.0^{b} \pm 1.0$ & $2.0^{b} \pm 1.2$ \\
\hline Citrus & $2.8^{\mathrm{a}} \pm 0.9$ & $3.3^{\mathrm{a}} \pm 1.1$ & $3.7^{\mathrm{a}} \pm 1.2$ & $2.9^{\mathrm{a}} \pm 1.1$ & $2.9^{\mathrm{a}} \pm 1.0$ & $2.8^{\mathrm{a}} \pm 1.1$ \\
\hline Banana & $1.9^{\mathrm{ab}} \pm 1.1$ & $1.4^{\mathrm{ab}} \pm 0.5$ & $2.9^{\mathrm{a}} \pm 1.1$ & $2.2^{\mathrm{ab}} \pm 1.1$ & $1.1^{\mathrm{b}} \pm 0.6$ & $1.3^{\mathrm{ab}} \pm 1.1$ \\
\hline Yeasty & $2.4^{\mathrm{a}} \pm 1.1$ & $2.7^{\mathrm{a}} \pm 1.2$ & $2.2^{\mathrm{a}} \pm 1.0$ & $2.6^{\mathrm{a}} \pm 1.2$ & $3.5^{\mathrm{a}} \pm 1.2$ & $3.1^{\mathrm{a}} \pm 1.3$ \\
\hline Chemical & $2.1^{\mathrm{b}} \pm 0.8$ & $2.1^{b} \pm 0.9$ & $2.3^{b} \pm 0.8$ & $2.3^{b} \pm 0.9$ & $3.6^{\mathrm{a}} \pm 1.2$ & $3.3^{\mathrm{a}} \pm 1.3$ \\
\hline Earthy & $2.3^{a} \pm 0.9$ & $2.5^{\mathrm{a}} \pm 1.1$ & $2.3^{\mathrm{a}} \pm 0.9$ & $4.2^{b} \pm 1.0$ & $4.0^{b} \pm 1.2$ & $4.1^{b} \pm 1.4$ \\
\hline Perfume & $3.8^{\mathrm{a}} \pm 1.0$ & $4.1^{\mathrm{a}} \pm 1.2$ & $2.8^{b} \pm 1.1$ & $2.9^{b} \pm 1.2$ & $3.8^{\mathrm{a}} \pm 1.2$ & $3.3^{\mathrm{ab}} \pm 1.2$ \\
\hline Mouldy & $1.6^{\mathrm{a}} \pm 1.0$ & $2.7^{b} \pm 0.9$ & $2.1^{\mathrm{ab}} \pm 1.1$ & $2.1^{\mathrm{ab}} \pm 1.0$ & $3.7^{c} \pm 1.1$ & $3.9^{c} \pm 1.4$ \\
\hline \multicolumn{7}{|l|}{ Taste/Mouthfeel } \\
\hline Sweet & $3.7^{\mathrm{a}} \pm 1.1$ & $5.8^{\mathrm{b}} \pm 1.4$ & $5.6^{\mathrm{ab}} \pm 1.4$ & $2.6^{c} \pm 1.1$ & $2.9^{c} \pm 1.3$ & $2.5^{c} \pm 1.0$ \\
\hline Sour & $4.6^{\mathrm{ab}} \pm 1.4$ & $3.4^{\mathrm{b}} \pm 1.1$ & $3.2^{b} \pm 1.2$ & $5.7^{\mathrm{a}} \pm 1.3$ & $5.1^{\mathrm{a}} \pm 1.3$ & $5.2^{\mathrm{a}} \pm 1.2$ \\
\hline Bitter & $3.8^{\mathrm{a}} \pm 1.1$ & $3.7^{\mathrm{a}} \pm 1.1$ & $2.5^{\mathrm{a}} \pm 1.1$ & $4.2^{\mathrm{ab}} \pm 1.1$ & $4.9^{b} \pm 1.1$ & $4.9^{b} \pm 1.0$ \\
\hline Salty & $0.9^{a} \pm 0.3$ & $0.7^{\mathrm{a}} \pm 0.2$ & $0.6^{\mathrm{a}} \pm 0.2$ & $0.8^{a} \pm 0.3$ & $0.8^{\mathrm{a}} \pm 0.2$ & $0.9^{a} \pm 0.2$ \\
\hline Astringency & $3.6^{\mathrm{a}} \pm 1.1$ & $3.9^{\mathrm{a}} \pm 1.1$ & $2.7^{\mathrm{a}} \pm 1.2$ & $4.4^{\mathrm{a}} \pm 1.0$ & $5.8^{b} \pm 1.5$ & $5.0^{\mathrm{b}} \pm 1.3$ \\
\hline Aftertaste & $4.2^{\mathrm{a}} \pm 1.0$ & $5.1^{\mathrm{a}} \pm 1.2$ & $4.2^{\mathrm{a}} \pm 1.4$ & $5.1^{\mathrm{a}} \pm 1.3$ & $5.3^{\mathrm{a}} \pm 1.0$ & $4.7^{a} \pm 1.3$ \\
\hline Acidic & $4.7^{\mathrm{a}} \pm 1.2$ & $4.1^{\mathrm{a}} \pm 1.2$ & $3.4^{a} \pm 1.3$ & $4.9^{\mathrm{a}} \pm 1.3$ & $4.2^{\mathrm{a}} \pm 1.2$ & $4.5^{\mathrm{a}} \pm 1.2$ \\
\hline Tannic & $2.4^{\mathrm{a}} \pm 0.8$ & $2.3^{\mathrm{a}} \pm 1.2$ & $2.7^{\mathrm{b}} \pm 1.1$ & $4.3^{b} \pm 1.4$ & $4.3^{b} \pm 1.2$ & $4.6^{\mathrm{b}} \pm 1.4$ \\
\hline
\end{tabular}

${ }^{1}$ Means in the same row, with the same letter, are not significantly different at $\alpha=0.05$.

The experienced panellists identified that the sweet ciders (S1, S2, S3) were significantly higher in sweetness than the dry ciders (D1, D2) $(p<0.05)$, as would be expected. They also indicated that the dry ciders were higher in sour and bitterness than the sweet ciders $(p<0.05)$. Past research has found that the bitter taste is associated with a group of flavours called heavy flavours, including woody, underwood, and animal [16]. In this study, the ciders that were higher in earthy and mouldy were associated with a bitter taste as well. These results also agree with the work completed by Qin et al. [1], as ciders identified as bitter were also associated with sourness. Moreover, the dry ciders were significantly more astringent than the sweet ciders $(p<0.05)$. Once again, agreeing with the previous study by Qin et al. [1], as they found astringency was also linked to ciders described as bitter and dry. The dry ciders were also found to be tannic and to possess an aftertaste. This result agrees with past work, as ciders containing an aftertaste were also associated with bitter, tart, and astringent by American and Chinese participants [41].

The experienced panellists evaluated the ciders consistently, as the replicates of D2 were not significantly different, and their results agree with past research on ciders. All panellists had participated in other sensory trials that had involved category scales, and they had been on at least one trained panel investigating an alcoholic beverage (wine or beer). This result agrees with past studies on experienced panellists, as they have been found to produce consistent results when using a sensory methodology they are familiar with [22,23]. Additionally, it agrees with Ares and Varela [18] who found that there is no superiority of trained panellists over consumers. However, there are some limitations to using experienced panellists, as no significant differences were found in some of the sensory properties (citrus, yeasty, salty, acidic), and trained panellists would probably have been able to identify small differences in the samples [42]. Overall, the experienced panellists evaluated the ciders using a static sensory methodology consistently; the next part of the study evaluated experienced panellists using an unfamiliar dynamic methodology: TCATA. 
The experienced panellists completed a CATA questionnaire that included all of the terms listed in Table 2. They were asked to select the attributes they felt were most important when evaluating cider. Based on the results, the terms sweet (16), sour (16), bitter (15), earthy (11), fresh apple (11), cooked apple (10), yeasty (9), and chemical (9) were selected to be included in the TCATA. Eight terms were selected to be included as that number of terms has been used in past research [43]. Figure 1 presents graphs based on the citation proportion of the sensory attributes for the sweet ciders subjected to TCATA. There was a high proportion of citations for sweet, sour, and bitter tastes for all sweet ciders, indicating the importance of these attributes. In cider S1, the bitter and sour tastes were cited quite frequently during the first $30 \mathrm{~s}$, while in S2 and S3, the experienced panellists frequently selected the sweet taste attribute. The fresh apple and earthy were also cited frequently during the first $30 \mathrm{~s}$ of evaluation. The attributes of cooked apple and chemical were used sparingly by panellists, and this is a limitation of asking the experienced panellists to select the terms included in the TCATA task. The experienced panellists believed these attributes were important, but not many panellists used these attributes when evaluating the cider. Sweet and sour attributes dominated the aftertaste of all the sweet ciders. A sour aftertaste was also found by American and Chinese participants when they evaluated ciders [41].

Figure 2 presents the results of the TCATA task with the dry ciders. The main difference is that the sour attribute dominates the dry ciders (D1, D2, D2 replicate) throughout the $90 \mathrm{~s}$ evaluation, especially in the first $45 \mathrm{~s}$ of the evaluation. The proportion of citations also shows a high incidence of bitterness and earthiness, agreeing with the static evaluation (Table 2). The aftertaste of the ciders was again associated with sour but also with bitterness. In contrast to sweet ciders, the chemical attribute was used more frequently throughout the evaluation, and the fresh apple attribute was not used very frequently. This result agrees with the intensity scores in Table 2, as D2 was significantly higher than all other ciders in terms of chemical aroma, and it was significantly lower in fresh apple aroma than all other ciders $(p<0.05)$. Once again, the cooked apple attribute was used sparingly and again indicates that allowing the experienced panellists to determine the attributes in the TCATA is a limitation of this study. Similar to past studies comparing TCATA and trained panels $[28,44]$, the results of the TCATA expanded on how the sensory attributes changed over time. The TCATA confirmed the results of the category scales (Table 2) and emphasized the differences in the initial tastes of the sweet and dry ciders.

The average proportion of citations of the attributes included in the TCATA task are outlined in Table 3. The dry ciders (D1 and D2) were found to be significantly higher in bitterness than the S2 and S3, in agreement with the category scales $(p<0.05$; Table 2). However, the average proportion of citations for the bitterness of S1 was not significantly different from the dry ciders (D1 and D2; $p<0.05$ ). S1 was also found to be significantly higher in citations for sourness than the other sweet ciders (S2 and S3; $p<0.05$ ). As expected, the sweet ciders had a significantly higher proportion of citations for sweetness than the dry ciders $(p<0.05)$. S1 also had a significantly higher citation proportion of the yeasty attribute than the other ciders $(p<0.05)$. In agreement with the category scales (Table 2), D2 had a higher proportion of citations for the chemical attribute than all other ciders $(p<0.05)$. The replicated cider sample's average proportion of citations was not significantly different for any of the attributes $(p<0.05)$, indicating that the experienced panellists were consistent. There were no significant differences in the average proportions of citations for the cooked apple, earthy, and fresh apple for the ciders, and as stated above, this may be because the experienced panellists were asked to select the attributes in the TCATA task.

Experienced panellists were used in this study to evaluate the ciders; however, they were not experienced with the TCATA. Rather they had experience with trained panels on alcoholic beverages, as well as projective mapping and consumer acceptability trials. Looking at the D2 replicate (Figure 2), the results in Table 3, and the TCATA difference curve (not pictured as they were very few differences), it appears that their experience 
with sensory methodology helped the experienced panellists create reproducible results when evaluating the same cider twice. However, as shown in Figures 1 and 2, none of the proportions of citations were above 0.8 . To increase the consistency of the results, many studies have used training sessions [29,37]. This study did involve a training session, but it did not include them practicing a TCATA evaluation but rather was a demonstration and training on the different sensory attributes. Future studies should include asking the experienced panellists to practice the TCATA task, as a more in-depth familiarization step has been shown to increase the ability to discriminate the samples [45].
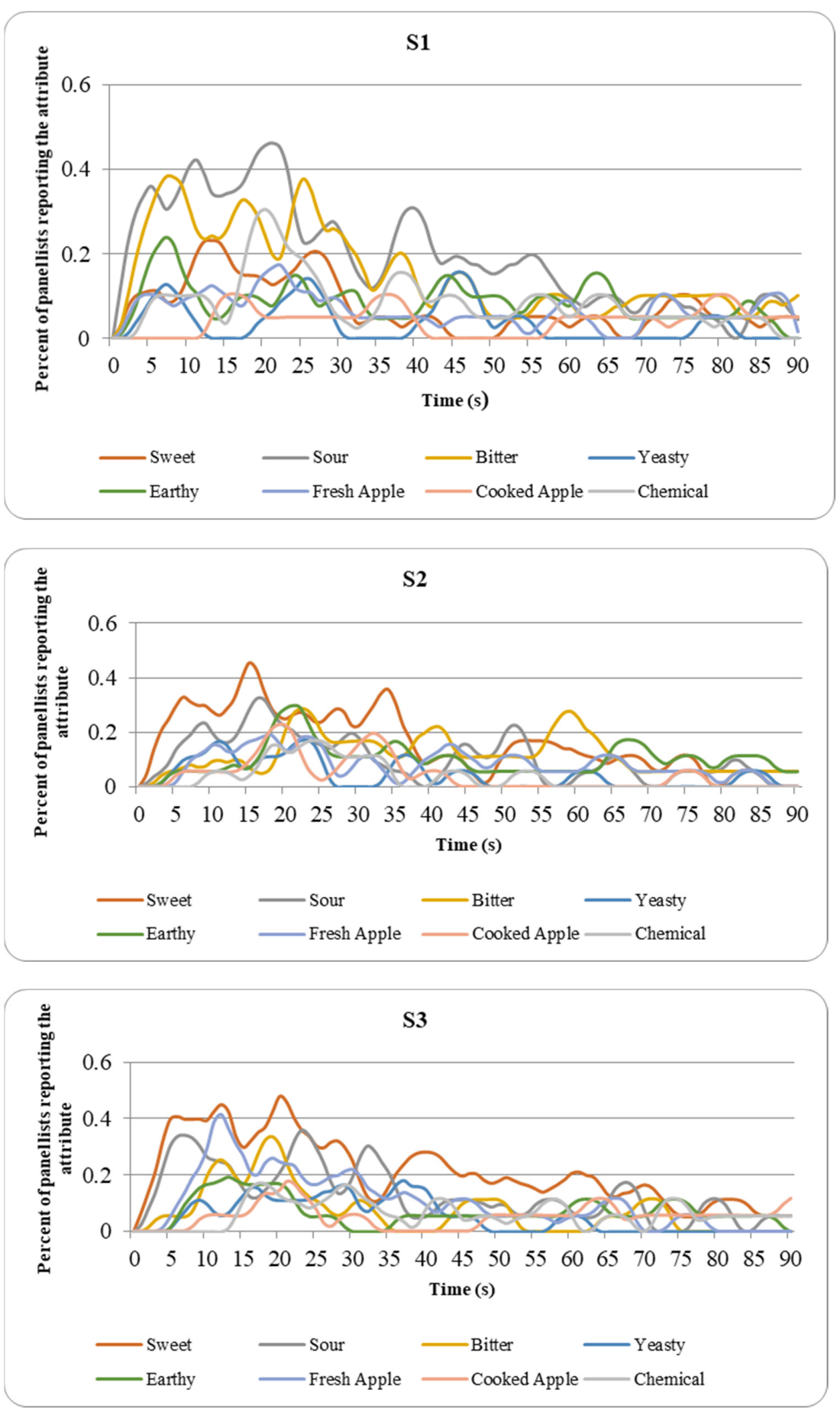

Figure 1. Temporal-check-all-that-apply of the sweet ciders. 

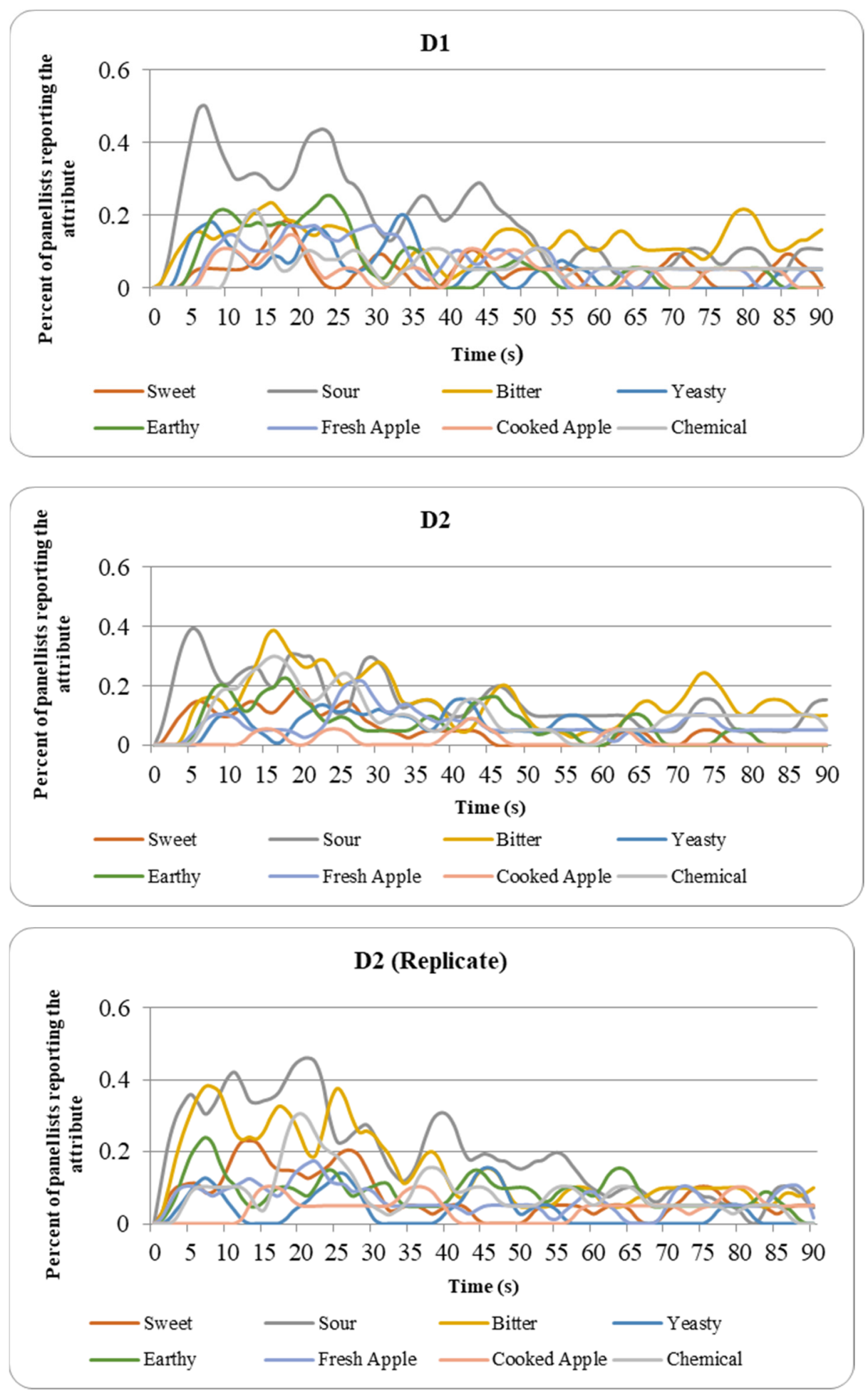

Figure 2. Temporal check-all-that-apply of the sweet ciders.

The experienced panellists were consistent when evaluating the ciders using a familiar methodology: category scales. A pool of experienced panellists (familiar with the sensory method) may help food companies and cideries save money when developing new products. However, more training is necessary if they are going to be using an unfamiliar method. This study has some limitations, as a small number of samples (six ciders) were involved. For the use of experienced panellists to be of value, they will have to evaluate a larger number of samples. In addition, only one replicate of testing was completed. 
Future studies should ask experienced panellists to complete multiple testing sessions to continue to evaluate the reproducibility of their evaluations. Additionally, this research only included ciders sold in Nova Scotia, Canada; future studies should investigate ciders available across Canada and North America. Another limitation is that the panellists chose the attributes included in the TCATA; however, not all of them were relevant during the evaluation. The colour of the ciders was similar, but they were evaluated under white light, and as stated above, there was a difference in the clarity that could have affected the panellists' evaluations.

Table 3. The average proportion of experienced panellists' citations of the TCATA sensory attributes.

\begin{tabular}{ccccccccc}
\hline Sample & Bitter & Chemical & Cooked Apple & Earthy & Fresh Apple & Sour & Sweet & Yeasty \\
\hline S1 & $0.146^{\mathrm{a}}$ & $0.048^{\mathrm{a}}$ & $0.033^{\mathrm{a}}$ & $0.082^{\mathrm{a}}$ & $0.125^{\mathrm{a}}$ & $0.225^{\mathrm{a}}$ & $0.179^{\mathrm{a}}$ & $0.100^{\mathrm{a}}$ \\
S2 & $0.117^{\mathrm{b}}$ & $0.037^{\mathrm{a}}$ & $0.044^{\mathrm{a}}$ & $0.101^{\mathrm{a}}$ & $0.081^{\mathrm{ab}}$ & $0.105^{\mathrm{b}}$ & $0.164^{\mathrm{a}}$ & $0.044^{\mathrm{b}}$ \\
S3 & $0.072^{\mathrm{c}}$ & $0.065^{\mathrm{a}}$ & $0.052^{\mathrm{a}}$ & $0.072^{\mathrm{a}}$ & $0.106^{\mathrm{a}}$ & $0.135^{\mathrm{b}}$ & $0.216^{\mathrm{a}}$ & $0.054^{\mathrm{b}}$ \\
D1 & $0.131^{\mathrm{a}}$ & $0.062^{\mathrm{a}}$ & $0.047^{\mathrm{a}}$ & $0.070^{\mathrm{a}}$ & $0.079^{\mathrm{b}}$ & $0.198^{\mathrm{a}}$ & $0.042^{\mathrm{b}}$ & $0.056^{\mathrm{b}}$ \\
D2 & $0.166^{\mathrm{a}}$ & $0.116^{\mathrm{b}}$ & $0.015^{\mathrm{a}}$ & $0.077^{\mathrm{a}}$ & $0.077^{\mathrm{b}}$ & $0.171^{\mathrm{a}}$ & $0.058^{\mathrm{b}}$ & $0.061^{\mathrm{b}}$ \\
D2 & $0.167^{\mathrm{a}}$ & $0.106 \mathrm{~b}$ & $0.046^{\mathrm{a}}$ & $0.088^{\mathrm{a}}$ & $0.073^{\mathrm{b}}$ & $0.213^{\mathrm{a}}$ & $0.084^{\mathrm{b}}$ & $0.037^{\mathrm{b}}$ \\
\hline
\end{tabular}

${ }^{1}$ Means in the same column, with the same letter, are not significantly different at $\alpha=0.05$.

\section{Conclusions}

The sweet ciders were associated with sweet, floral, fresh apple, and cooked apple attributes, and they had a sour aftertaste. The dry ciders were bitter, sour, earthy, and mouldy, and they had a sour and bitter aftertaste. The experienced panellists could produce reproducible results using both methodologies; however, an in-depth training step is encouraged if the experienced panellists are using an unfamiliar task. Overall, more studies need to be completed utilizing experienced panellists and investigating the sensory properties of ciders. Future research should include a wider range of ciders on the North American market. Additionally, trained panellists could be used to determine small differences between the sensory properties of the ciders. Studies should investigate the aftertaste of ciders and the effect of carbonation on the sensory properties of ciders.

Supplementary Materials: The following are available online at https:/ / www.mdpi.com/article/10 $.3390 /$ beverages7020024/s1, Table S1: Attributes evaluated by the experienced panellists.

Author Contributions: Conceptualization R.M., S.B. and M.B.M.; methodology, M.B.M.; software, M.B.M.; validation, R.M., S.B. and M.B.M.; formal analysis, R.M., S.B. and M.B.M.; investigation, R.M., S.B. and M.B.M.; resources, M.B.M.; data curation, M.B.M.; writing—original draft preparation, R.M. and S.B.; writing-review and editing, M.B.M.; visualization, M.B.M.; supervision, M.B.M.; project administration, M.B.M.; funding acquisition, M.B.M. All authors have read and agreed to the published version of the manuscript.

Funding: This research was funded by the Centre for the Sensory Research of Food.

Institutional Review Board Statement: The study was conducted according to the guidelines of the Declaration of Helsinki, and approved by the Acadia University Research Ethics Board (REB 21-16).

Informed Consent Statement: Informed consent was obtained from all subjects involved in the study.

Data Availability Statement: The data presented in this study are available on request from the corresponding author. The data are not publicly available to maintain the confidentiality of participants.

Acknowledgments: Thanks to all the volunteers who participated in this project.

Conflicts of Interest: The authors declare no conflict of interest.

\section{References}

1. Qin, Z.; Petersen, M.A.; Bredie, W.L.P. Flavor Profiling of Apple Ciders from the UK and Scandinavian Region. Food Res. Int. 2018, 105, 713-723. [CrossRef] [PubMed]

2. Way, M.L.; Jones, J.E.; Nichols, D.S.; Dambergs, R.G.; Swarts, N.D. A Comparison of Laboratory Analysis Methods for Total Phenolic Content of Cider. Beverages 2020, 6, 55. [CrossRef] 
3. Tozer, P.R.; Galinato, S.P.; Ross, C.F.; Miles, C.A.; McCluskey, J.J. Sensory Analysis and Willingness to Pay for Craft Cider*. J. Wine Econ. 2015, 10, 314-328. [CrossRef]

4. Dos Santos, C.M.E.; Alberti, A.; Pietrowski, G.D.A.M.; Zielinski, A.A.F.; Wosiacki, G.; Nogueira, A.; Jorge, R.M.M. Supplementation of Amino Acids in Apple Must for the Standardization of Volatile Compounds in Ciders. J. Inst. Brew. 2016, 122, 334-341. [CrossRef]

5. Thompson-Witrick, K.A.; Goodrich, K.M.; Neilson, A.P.; Hurley, E.K.; Peck, G.M.; Stewart, A.C. Characterization of the Polyphenol Composition of 20 Cultivars of Cider, Processing, and Dessert Apples (Malus $\times$ Domestica Borkh.) Grown in Virginia. J. Agric. Food Chem. 2014, 62, 10181-10191. [CrossRef] [PubMed]

6. Sanoner, P.; Guyot, S.; Marnet, N.; Molle, D.; Drilleau, J.F. Polyphenol Profiles of French Cider Apple Varieties (Malus Domestica Sp.). J. Agric. Food Chem. 1999, 47, 4847-4853. [CrossRef]

7. Girschik, L.; Jones, J.E.; Kerslake, F.L.; Robertson, M.; Dambergs, R.G.; Swarts, N.D. Apple Variety and Maturity Profiling of Base Ciders Using UV Spectroscopy. Food Chem. 2017, 228, 323-329. [CrossRef] [PubMed]

8. Torija, M.J.; Rozès, N.; Poblet, M.; Guillamón, J.M.; Mas, A. Effects of Fermentation Temperature on the Strain Population of Saccharomyces Cerevisiae. Int. J. Food Microbiol 2003, 80, 47-53. [CrossRef]

9. Dos Santos, C.M.E.; Pietrowski, G.A.M.; Braga, C.M.; Rossi, M.J.; Ninow, J.; Dos Santos, T.P.M.; Wosiacki, G.; Jorge, R.M.M.; Nogueira, A. Apple Aminoacid Profile and Yeast Strains in the Formation of Fusel Alcohols and Esters in Cider Production. J. Food Sci. 2015, 80, C1170-C1177. [CrossRef] [PubMed]

10. Rodríguez Madrera, R.; García Hevia, A.; Suárez Valles, B. Comparative Study of Two Aging Systems for Cider Brandy Making. Changes in Chemical Composition. LWT-Food Sci. Technol. 2013, 54, 513-520. [CrossRef]

11. Ye, M.; Yue, T.; Yuan, Y. Evolution of Polyphenols and Organic Acids during the Fermentation of Apple Cider. J. Sci. Food Agric. 2014, 94, 2951-2957. [CrossRef] [PubMed]

12. Bortolini, D.G.; Benvenutti, L.; Demiate, I.M.; Nogueira, A.; Alberti, A.; Zielinski, A.A.F. A New Approach to the Use of Apple Pomace in Cider Making for the Recovery of Phenolic Compounds. LWT 2020, 126, 109316. [CrossRef]

13. Delage, E.; Bohuon, G.; Baron, A.; Drilleau, J.F. High-Performance Liquid Chromatography of the Phenolic Compounds in the Juice of Some French Cider Apple Varieties. J. Chromatogr. A 1991, 555, 125-136. [CrossRef]

14. Ye, M.; Yue, T.; Yuan, Y. Changes in the Profile of Volatile Compounds and Amino Acids during Cider Fermentation Using Dessert Variety of Apples. Eur. Food Res. Technol. 2014, 239, 67-77. [CrossRef]

15. Gomis, D.B.; Tamayo, D.M.; Alonso, J.M. Determination of Monosaccharides in Cider by Reversed-Phase Liquid Chromatography. Anal. Chim. Acta 2001, 436, 173-180. [CrossRef]

16. Le Quéré, J.M.; Husson, F.; Renard, C.M.G.C.; Primault, J. French Cider Characterization by Sensory, Technological and Chemical Evaluations. LWT-Food Sci. Technol. 2006, 39, 1033-1044. [CrossRef]

17. Farris, J.; Malone, T.; Robison, L.J.; Rothwell, N.L. Is “Localness" about Distance or Relationships? Evidence from Hard Cider. J. Wine Econ. 2019, 14, 252-273. [CrossRef]

18. Ares, G.; Varela, P. Trained vs. Consumer Panels for Analytical Testing: Fueling a Long Lasting Debate in the Field. Food Qual. Prefer. 2017, 61, 79-86. [CrossRef]

19. Stone, H.; Bleibaum, R.N.; Thomas, H.A. Sensory Evaluation Practices; Academic Press: Cambridge, MA, USA, 2012.

20. Castura, J.C.; Findlay, C.J.; Lesschaeve, I. Monitoring Calibration of Descriptive Sensory Panels Using Distance from Target Measurements. Food Qual. Prefer. 2005, 16, 682-690. [CrossRef]

21. Michon, C.; McDonnell, E. Validation of a Degree of Difference (DOD) Cut-off Point Using Cross-Cultural Insight for Quality Purposes. Food Qual. Prefer. 2008, 19, 727-733. [CrossRef]

22. Morin, M.; Hayward, L.; McSweeney, M.B. Use of Experienced Panelists and the Projective Mapping Task in Comparison to Trained Panelists and Naïve Consumers. J. Sens. Stud. 2018, 33, e12463. [CrossRef]

23. Barton, A.; Hayward, L.; Richardson, C.D.; McSweeney, M.B. Use of Different Panellists (Experienced, Trained, Consumers and Experts) and the Projective Mapping Task to Evaluate White Wine. Food Qual. Prefer. 2020, 83, 103900. [CrossRef]

24. Castura, J.C.; Antúnez, L.; Giménez, A.; Ares, G. Temporal Check-All-That-Apply (TCATA): A Novel Dynamic Method for Characterizing Products. Food Qual. Prefer. 2016, 47, 79-90. [CrossRef]

25. Baker, A.K.; Castura, J.C.; Ross, C.F. Temporal Check-All-That-Apply Characterization of Syrah Wine. J. Food Sci. 2016, 81, S1521-S1529. [CrossRef] [PubMed]

26. de Souza Paglarini, C.; Vidal, V.A.S.; Dos Santos, M.; Coimbra, L.O.; Esmerino, E.A.; Cruz, A.G.; Pollonio, M.A.R. Using Dynamic Sensory Techniques to Determine Drivers of Liking in Sodium and Fat-Reduced Bologna Sausage Containing Functional Emulsion Gels. Food Res. Int. 2020, 132, 109066. [CrossRef]

27. Schumaker, M.R.; Diako, C.; Castura, J.C.; Edwards, C.G.; Ross, C.F. Influence of Wine Composition on Consumer Perception and Acceptance of Brettanomyces Metabolites Using Temporal Check-All-That-Apply Methodology. Food Res. Int. 2019, 116, 963-972. [CrossRef]

28. McMahon, K.M.; Culver, C.; Castura, J.C.; Ross, C.F. Perception of Carbonation in Sparkling Wines Using Descriptive Analysis (DA) and Temporal Check-All-That-Apply (TCATA). Food Qual. Prefer. 2017, 59, 14-26. [CrossRef]

29. Mitchell, J.; Castura, J.C.; Thibodeau, M.; Pickering, G. Application of TCATA to Examine Variation in Beer Perception Due to Thermal Taste Status. Food Qual. Prefer. 2019, 73, 135-142. [CrossRef] 
30. Wei, J.; Wang, S.; Zhang, Y.; Yuan, Y.; Yue, T. Characterization and Screening of Non-Saccharomyces Yeasts Used to Produce Fragrant Cider. LWT 2019, 107, 191-198. [CrossRef]

31. Antón, M.J.; Suárez Valles, B.; García Hevia, A.; Picinelli Lobo, A. Aromatic Profile of Ciders by Chemical Quantitative, Gas Chromatography-Olfactometry, and Sensory Analysis. J. Food Sci. 2014, 79, S92-S99. [CrossRef] [PubMed]

32. Symoneaux, R.; Guichard, H.; Le Quéré, J.M.; Baron, A.; Chollet, S. Could Cider Aroma Modify Cider Mouthfeel Properties? Food Qual. Prefer. 2015, 45, 11-17. [CrossRef]

33. Husson, F.; Bocquet, V.; Pagès, J. Use of Confidence Ellipses in a Pca Applied to Sensory Analysis Application to the Comparison of Monovarietal Ciders. J. Sens. Stud. 2004, 19, 510-518. [CrossRef]

34. Piggott, J.R.; Watson, M.P. A Comparison of Free-Choice Profiling and the Repertory Grid Method in the Flavor Profiling of Cider. J. Sens. Stud. 1992, 7, 133-145. [CrossRef]

35. Ares, G.; Jaeger, S.R.; Bava, C.M.; Chheang, S.L.; Jin, D.; Gimenez, A.; Vidal, L.; Fiszman, S.M.; Varela, P. CATA Questions for Sensory Product Characterization: Raising Awareness of Biases. Food Qual. Prefer. 2013, 30, 114-127. [CrossRef]

36. Meyners, M.; Castura, J.C. Randomization of CATA Attributes: Should Attribute Lists Be Allocated to Assessors or to Samples? Food Qual. Prefer. 2016, 48, 210-215. [CrossRef]

37. Kemp, B.; Trussler, S.; Willwerth, J.; Inglis, D. Applying Temporal Check-All-That-Apply (TCATA) to Mouthfeel and Texture Properties of Red Wines. J. Sens. Stud. 2019, 34, e12503. [CrossRef]

38. Ares, G.; Alcaire, F.; Antúnez, L.; Vidal, L.; Giménez, A.; Castura, J.C. Identification of Drivers of (Dis)Liking Based on Dynamic Sensory Profiles: Comparison of Temporal Dominance of Sensations and Temporal Check-All-That-Apply. Food Res. Int. 2017, 92, 79-87. [CrossRef] [PubMed]

39. Kessinger, J.; Earnhart, G.; Hamilton, L.; Phetxumphou, K.; Neill, C.; Stewart, A.C.; Lahne, J. Exploring Perceptions and Categorization of Virginia Hard Ciders through the Application of Sorting Tasks. J. Am. Soc. Brew. Chem. 2021, 79, 187-200. [CrossRef]

40. Włodarska, K.; Pawlak-Lemańska, K.; Górecki, T.; Sikorska, E. Perception of Apple Juice: A Comparison of Physicochemical Measurements, Descriptive Analysis and Consumer Responses. J. Food Qual. 2016, 39, 351-361. [CrossRef]

41. Jamir, S.M.R.; Stelick, A.; Dando, R. Cross-Cultural Examination of a Product of Differing Familiarity (Hard Cider) by American and Chinese Panelists Using Rapid Profiling Techniques. Food Qual. Prefer. 2020, 79, 103783. [CrossRef]

42. Chambers, D.H.; Allison, A.M.A.; Chambers, E. Training Effects on Performance of Descriptive Panelists. J. Sens. Stud. 2004, 19, 486-499. [CrossRef]

43. Wu, A.Z.; Lee, R.W.; Calvé, B.L.; Cayeux, I. Temporal Profiling of Simplified Lemonade Using Temporal Dominance of Sensations and Temporal Check-All-That-Apply. J. Sens. Stud. 2019, 34, e12531. [CrossRef]

44. McCain-Keefer, H.R.; Meals, S.; Drake, M. The Sensory Properties and Consumer Acceptance of Cold Brew Coffee. J. Sens. Stud. 2020, 35, e12604. [CrossRef]

45. Jaeger, S.R.; Beresford, M.K.; Hunter, D.C.; Alcaire, F.; Castura, J.C.; Ares, G. Does a Familiarization Step Influence Results from a TCATA Task? Food Qual. Prefer. 2017, 55, 91-97. [CrossRef] 